Tropical Journal of Pharmaceutical Research May 2017; 16 (5): 1029-1037

ISSN: $1596-5996$ (print); 1596-9827 (electronic)

(c) Pharmacotherapy Group, Faculty of Pharmacy, University of Benin, Benin City, 300001 Nigeria.

All rights reserved.

Available online at http://www.tjpr.org

Original Research Article

http://dx.doi.org/10.4314/tjpr.v16i5.9

\title{
Neuroprotective effects of thymoquinone against cerebellar histopathological changes in propylthiouracil- induced hypothyroidism in adult rats
}

\author{
Ebtesam Mohammed AL Jehani ${ }^{1}$, Samar Alsaggaf ${ }^{2}$, Wafaa S Ramadan ${ }^{2,3 *}$ and \\ Soad Shaker $\mathrm{Ali}^{2}$ \\ ${ }_{1}^{1}$ Faculty of Applied Medical Sciences, ${ }^{2}$ Department of Anatomy, Faculty of Medicine, King Abdulaziz University, Jeddah, Saudi \\ Arabia, ${ }^{3}$ Department of Anatomy, Faculty of Medicine, Ain Shams University, Cairo, Egypt \\ *For correspondence: Email: wramadhan@kau.edu.sa,wsaadeldin@hotmail.com
}

\begin{abstract}
Purpose: To evaluate the effects of thymoquinone (TQ) on histological and immunohistochemical changes in the cerebellar cortex induced by propylthiouracil (PTU) treatment in rats.

Methods: Thirty-two adult male albino rats were randomly divided into four groups: C, control; PTU, treatment with oral PTU to induce hypothyroidism; TQ, treatment with TQ; and PTU + TQ, concomitant treatment with oral PTU and TQ for 6 weeks. Cavalieri's principle and physical dissector methods were employed for unbiased deduction of cerebellar granular layer volume, numerical density, and number of granular cells.

Results: In the PTU group, hematoxylin and eosin (H\&E)-stained sections revealed degeneration of Purkinje cells, neuronal loss, and spongiosis in the white matter. A decrease in the number of astrocytes-expressing glial fibrillary acidic protein (GFAP) and a significant decrease in granular layer cell density were also seen. Concomitant administration of TQ ameliorated histopathological changes, increased the proportion of GFAP-positive astrocytes, increased granular cell density, and significantly $(p<0.05)$ increased the levels of thyroid-stimulating hormones, T3 and T4.

Conclusion: TQ treatment significantly decreases cerebellar changes resulting from PTU-induced hypothyroidism, and results in the retention of neuronal structural integrity in the cerebellar cortex.
\end{abstract}

Keywords: Hypothyroidism, Cerebellum, Thymoquinone, Stereology, Glial fibrillary acidic protein, Neuronal structural integrity

Tropical Journal of Pharmaceutical Research is indexed by Science Citation Index (SciSearch), Scopus, International Pharmaceutical Abstract, Chemical Abstracts, Embase, Index Copernicus, EBSCO, African Index Medicus, JournalSeek, Journal Citation Reports/Science Edition, Directory of Open Access Journals (DOAJ), African Journal Online, Bioline International, Open-J-Gate and Pharmacy Abstracts

\section{INTRODUCTION}

Several studies have demonstrated that the cerebellum mainly functions to coordinate motor functions and control muscle tone and balance. However, the disruption of cerebellar circuitry by any structural impairment could hinder the processing of emotional responses and cause significant personality changes [1]. Therefore, sufficient thyroid function is necessary for normal development of the brain and life-long cognitive function [2]. Previous studies have shown that a thyroid hormone $(\mathrm{TH})$ deficiency in adulthood is associated with common cognitive deficits, including reduced general awareness, attention, learning, memory, and psychomotor pace [3].

Hypothyroidism can occur as a result of thyroid gland surgery following radiation in head and neck malignancies. latrogenic hypothyroidism was also reported in a previous pharmacological study [4]. The majority of dietary supplements fail 
to meet the scientific requirements necessary for treatment of hypothyroidism [5]. Since 1980, the World Health Organization has encouraged countries to identify and utilize traditional medicine and phytotherapy.

One natural option is the black seed Nigella sativa Linn (N.S.). Thymoquinone (TQ) is the bioactive phytochemical component of its oil (54 $\%$, and has been shown to have antiinflammatory, anti-oxidant, and anti-neoplastic effects both in vitro and in vivo [6]. The objective of this study was to determine the potential protective effects of TQ against cerebellar histopathological changes in propylthiouracil (PTU)-induced hypothyroidism in rats.

\section{EXPERIMENTAL}

\section{Animals}

Thirty-two adult male Wister rats (180-200 g each) were purchased from the Animal House Unit at King Fahd Medical Research Center (KFMRC), King Abdulaziz University, Saudi Arabia. The rats were randomly divided into cages $(42 \times 26.5 \times 15 \mathrm{~cm})$ and maintained at 22 $\pm 1{ }^{\circ} \mathrm{C}$ and $60 \%$ humidity. Animal care conformed to the KFMRC Institutional Guidelines for animals. The study was approved by Ethical Committee for Animal Research at King Abdulaziz University (approval no. HA-02-j-08). All animals received care according to the method approved under institutional guidelines for care and use of laboratory animals in KFMRC in accordance with "Principles of Laboratory Animal Care" and the Declaration of Helsinki, as amended in 2000 [7].

\section{Chemicals and drugs}

Thymoqinone (TQ) and propylthiouracil (PTU) (C7H10N2OS) were purchased from SigmaAldrich (USA). Kits for T4, T3, and thyroidstimulating hormone (TSH) were purchased from Biosystem Cadama USCN (UK).

\section{Chemical preparation}

PTU (6 mg/kg) was prepared by dissolving in warm water and was administered by gastric gavage for 6 weeks [8]. Rats with serum T4 and T3 concentrations less than control were considered to have hypothyroidism. PTU reduces circulating T3 and T4 levels, resulting in a hypothyroid state in rats [9]. TQ was dissolved in a few drops of dimethyl sulfoxide (DMSO) and diluted $1: 100$ in $0.9 \% \mathrm{NaCl}$. TQ was administrated orally every day at a dose of 10 $\mathrm{mg} / \mathrm{kg}$ via gastric gavage [10].

\section{Animal studies}

Four groups containing 8 rats each were treated as follows: Group 1 (cont) received pure water equal to the amount of PTU as a control; Group 2 (PTU) received $6 \mathrm{mg} / \mathrm{kg}$ of PTU by gastric gavage for 6 weeks to induce hypothyroidism; Group 3 (TQ) was treated with TQ (10 mg/kg per day) added to drinking water for 6 weeks; and Group 4 (PTU $+T Q$ ) received $T Q$ and PTU at the same dose and duration as Groups 2 and 3.

\section{Confirmation of hypothyroidism}

Thyroid function was evaluated after 6 weeks. Blood was collected from the retro-orbital venous plexus sinus using a $5-\mathrm{mL}$ capillary tube [11]. Serum was prepared by centrifuging the blood for $15 \mathrm{~min}$ at $3,000 \mathrm{~g}$ at $4{ }^{\circ} \mathrm{C}$ and kept at $-80{ }^{\circ} \mathrm{C}$ until analysis. A competitive inhibition enzyme immunoassay technique was used to assess serum T4, T3, and TSH.

\section{Tissue preparation for histopathology and stereological studies}

All animals were sacrificed by cervical dislocation. Dissection was performed after aortic perfusion with $60 \mathrm{~mL}$ of heparinized physiological saline, followed by $375 \mathrm{~mL}$ of $4.0 \%$ ice-cold paraformaldehyde in $0.1 \mathrm{M}$ phosphate buffer $(\mathrm{pH}$ $=7.4)$. The extracted brains were fixed at $3{ }^{\circ} \mathrm{C}$ for $3 \mathrm{~h}$, and then cut into equal halves along the sagittal plane. Cavalieri's principle was employed and serial equidistant sections of the right cerebellar hemisphere were cut along the coronal plane using a rotary microtome at $1 \mu \mathrm{m}$. The sections were successively collected in 0.01 $M$ phosphate buffered saline (PBS), and the whole number was estimated [12]. In total, 2,700 - 3,200 sections were cut through the entire cerebellar half. From these sections, an average of $15-20$ was randomly chosen in a systematic manner from the first 250 sections. To estimate cell volume, vertical sections were prepared from the other cerebellar half [13]. Sections were processed and stained with hematoxylin and eosin (H\&E) for quantitative analysis [14].

\section{Immunohistochemistry}

A protocol for antigen retrieval using a microwave oven was followed. Sections were placed in a 1:500 dilution of mouse polyclonal rabbit anti-glial fibrillary acidic protein (GFAP) overnight at $4{ }^{\circ} \mathrm{C}$. The sections were then incubated in a goat anti-rabbit IgG (1:100) and rabbit PAP (peroxidase-antiperoxidase) (1:50) for $1 \mathrm{~h}$, and then washed, placed in mouse peroxidase-antiperoxidase solution for $1 \mathrm{~h}$ 
(1:200), and finally placed in a 3,3'diaminobenzidine tetrahydrochloride (DAB) and hydrogen peroxide solution for $10 \mathrm{~min}$. Slides were cover-slipped with aqueous mounting medium. The contribution of nonspecific staining was monitored using negative controls [15].

\section{Evaluation of GFAP-stained cells}

The percentage of GFAP-reactive cerebellum was measured using Image-Pro Plus version 4.5 software (Media Cybernetics, Silver Springs, Maryland, USA). Color channel preference was employed before the area percentage was measured. The threshold parameters were kept constant across all groups. Five non-overlapping visual fields $(100 x)$ in 10 sections were examined for each animal.

\section{Stereology}

Stereology is a reliable and unbiased mathematical method used for the threedimensional (3-D) evaluation of structures using 2-D sections [16]. This method was used to evaluate the numerical density of granular cells as described below. The numerical density of granular cells was evaluated by the physical disector method. The disector represents the least definitive approach to a 3-D probe. It consists of a pair of sequential sections, a "reference" section, an adjacent section, and a "look-up" section. According to the disector method, granular cells that appear in the reference section and not in the look-up section should be counted. This method is a thematic calculation of numerical density [17]. In this study, the randomly chosen section of reference and its look-up section were photographed. A transparent point-counting grid was then randomly placed on the reference section and then mounted on the same area of the look-up section. The widest granular nuclei in focus within the grid and within the right vertical and top grid bars (acceptance line) were included in the count. Cells outside of the left vertical and bottom bars (forbidden line) were not counted. Therefore, the total number of granular nuclei appearing in the "reference" section photograph and not in the "look-up" sections was counted [18]. The numerical density was calculated as in Eq 1 [17].

$N A=(1 /\{a / f h\})(\Sigma Q / \Sigma P)$

where NA is the numerical density of granular neurons, $Q$ is the number of profiles seen in the reference section, a/f is the area associated with each frame, $\mathrm{h}$ is the distance between sections, and $P$ is the number of frame-associated points hitting the tissue.

The total number of granular cells was calculated as follows as in Eq 2.

$N=N V \times V($ ref $)$

where $\mathrm{N}$ is the total number of granule neurons, $\mathrm{NV}$ is the volume of the granular layer, and V(ref) is the numerical density of granule neurons.

\section{Statistical analysis}

Data were statistically analyzed and presented as mean \pm standard deviation (SD) using SPSS version 16 (IBM, USA). A one-way analysis of variance (ANOVA) was used; when equal variance could be assumed, the post-hoc least significant difference (LSD) $t$-test was applied. $P$ $<0.05$ was considered statistically significant.

\section{RESULTS}

The body weight differences among the groups after 6 weeks of treatment are shown in Figure 1.

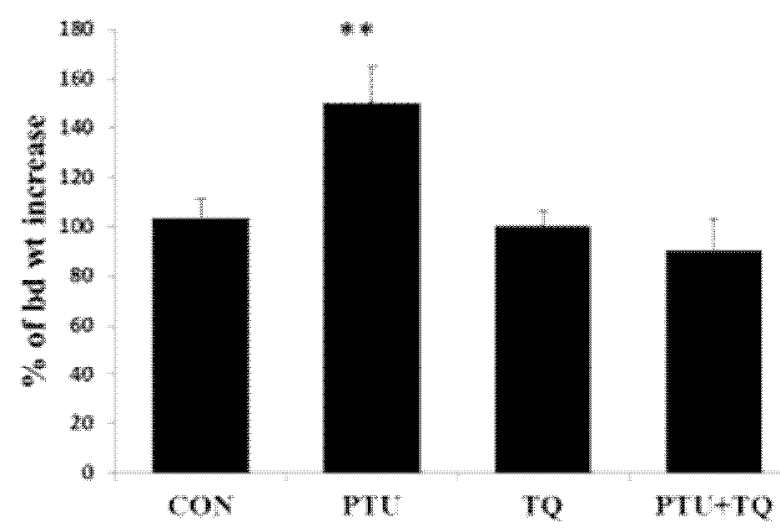

Figure 1: The percent body (bd wt) difference of animals between the beginning and the end of the experiment. Hypothyroid model rats (PTU) showed a significant increase in body weight compared with the other groups. A one-way analysis of variance (ANOVA) was used for statistical analysis and values are expressed as mean \pm standard deviation (SD). CON: Control, PTU: propylthiouracil, TQ: thymoquinone, ${ }^{* *} p<0.01$

\section{Biochemical profile}

Table 1 shows serum TSH, T3, and T4 levels. T3 and T4 levels lower than the control were considered to indicate hypothyroid status. Administration of TQ restored thyroid hormones to control levels. 
Table 1: The levels of thyroid-stimulating hormone (TSH; mlU/L), T3 $(\mathrm{pg} / \mathrm{mL})$, and T4 $(\mathrm{pg} / \mathrm{mL})$ after 6 weeks of treatment.

\begin{tabular}{lcccc}
\hline Parameter & Group 1: Con & Group 2: PTU & Group 3: TQ & Group 4: PTU + TQ \\
\hline TSH $(\mathrm{mlU} / \mathrm{L})$ & $3.40 \pm 1.32$ & $18.5 \pm 3.01$ & $3.50 \pm 0.32$ & $2.51 \pm 0.54$ \\
T3 $(\mathrm{pg} / \mathrm{mL})$ & $3.73 \pm 0.67$ & $0.62 \pm 0.18$ & $4.04 \pm 0.25$ & $3.25 \pm 0.08$ \\
T4 $(\mathrm{pg} / \mathrm{mL})$ & $26.19 \pm 1.31$ & $0.31 \pm 0.09$ & $29.1 \pm 1.14$ & $32.3 \pm 1.44$ \\
\hline
\end{tabular}

$A$ one-way analysis of variance (ANOVA) was used for statistical analysis. When equal variance could be assumed, the least significant difference (LSD) t-test was applied. Data are presented as mean \pm standard deviation (SD). $P<0.05$ was considered significant
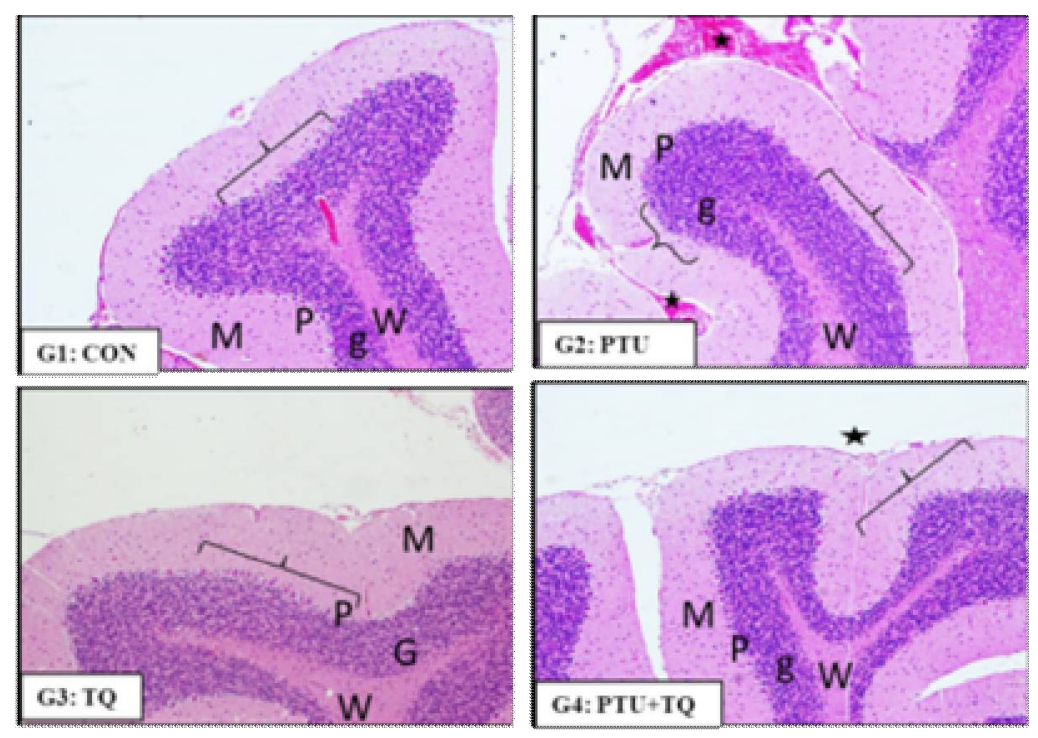

Figure 2: Photomicrographs of cerebellar folia showing normal molecular (M), Purkinje (P), and granular $(G)$ layers and deep white matter (W) in Group 1 (Cont) and Group 3 (TQ). Marked vascular congestion and blood extravasation can be seen under the raised meningeal covering (stars), and wide regions of neuronal loss (brackets) are evident in Group 2 (PTU). Sections were stained with hematoxylin and eosin (H\&E) and images were acquired at $\mathrm{X} 40$

\section{Histopathological features}

Examination of cerebellar folia sections at low magnification revealed three major layers: an outer layer lightly stained with molecular markers, a middle Purkinje layer, and an inner granular layer. A white matter core appeared in the deep folia. Sections from the PTU-induced hypothyroid group (Group 2) had a raised meningeal covering with marked congestion of the underlying vessels and extravasation of blood. This was in addition to wide areas of neuronal loss and increased frequency of Purkinje cell deformation and degeneration compared with other groups. Compared with untreated groups, the cerebral folia in Group 3 (TQ) had a normal histological structure and no signs of subpial hemorrhage or vascular congestion. Most Group 4 folia showed normal Purkinje cells, and the histological cerebellar folia characteristics did not differ from the control (Figure 2).

When examined at higher magnification, sections of the control group (Group 1) revealed darkly stained scattered basket cells in the molecular layer. The large cell bodies of Purkinje cells had pale nuclei and prominent nucleoli with branching dendrites, while numerous small granular cells were densely packed in the inner granular layer. These cells had rounded dark nuclei and little cytoplasm. A group of large Golgi II cell nuclei were prominent between the molecular and granular layers (Figure 3).

In Group 2 (PTU) animals, vacuolation of the molecular layer was observed. Focal regions of Purkinje cell loss were noticed, and other regions showed marked deformity. The cells were shrunken, with an irregular outline, deeply stained cytoplasm, and small pyknotic nuclei. Some degenerated cells were also seen in the granular layer (Figure 3). Group 3 rats showed normal Purkinje cells with larger euchromatic nuclei and well-formed dendrites (Figure 3). In Group 4, Purkinje cells had highly basophilic cytoplasm, large vesicular nuclei with prominent nucleoli, and axonal arborization indicating cell activation (Figure 3 ). 


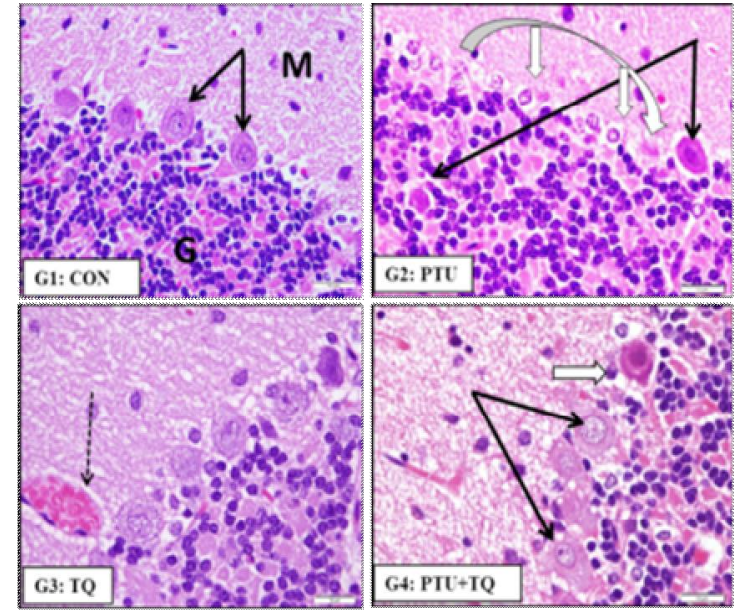

Figure 3: Photomicrographs of Group 1 cerebellar cortex samples showing Purkinje cells with basophilic cytoplasm and rounded nuclei (thin black arrows). Numerous small granular cells are densely packed in the granular layer (G) and basket cells are scattered in the molecular layer. Group 2 photomicrographs show shrunken Purkinje cells, lost in focal areas (curved arrow), have deeply stained cytoplasm, irregular outlines, and small pyknotic nuclei. Few are seen in the granular layer (double black arrow). Vacuolated basket cells are also noted (white arrows). M: molecular layer; Sections were stained with H\&E and images were acquired at $x 40$

The cerebellar white matter revealed increased areas of vacuolation (spongiosis) and congested vessels in the PTU group compared with other groups. In the TQ groups, the white mater showed a generally normal structure (Figure 4).

\section{Immunohistochemical profile}

GFAP-reactive astrocytes in Group 1 had a small amount of cytoplasm with long processes. The cell bodies were found within the Purkinje cell layer, granule cell layer, and white matter core. The processes extended through the molecular layer. In Group 2, a diffuse but significant decrease in the expression of GFAP in astrocytes was observed. In Group 3, cerebellum sections revealed no alteration in the distribution of the GFAP-immunolabeled astrocytes. In Group 4, the expression GFAP in astrocytes was enhanced (Figure 5).

\section{GFAP-stained astrocyte area}

The area containing GFAP-stained astrocytes was significantly decreased in Group 2. Only 9.3 $\%$ of sections contained GFAP astrocytes compared with Group 1 (35.04\%). Administration of TQ in Group 4 increased the area of GFAPpositive astrocytes to $23.04 \%$ (Figure 6).

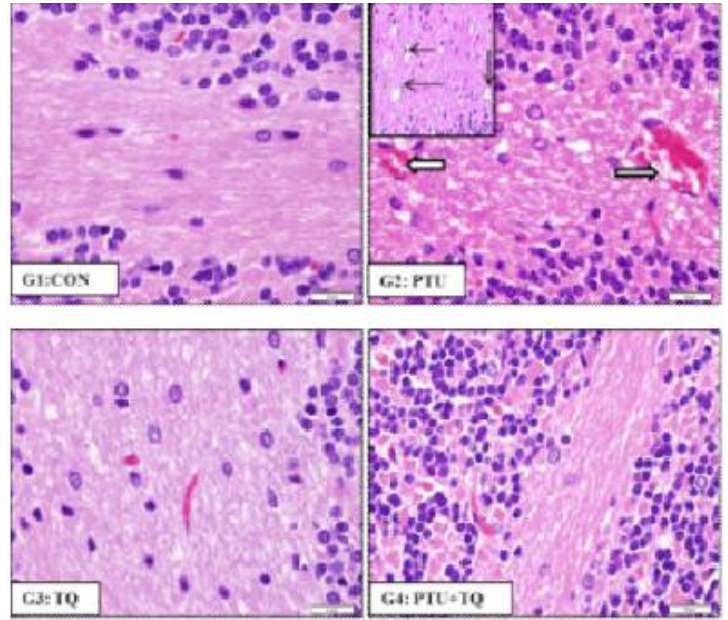

Figure 4: Photomicrographs of the white matter core in the cerebellar folia. Group 1 shows normal structure of the inner white matter. Congested vessels (white arrows) and areas of vacuolation (inset) are observed in group 2. Both groups 3 and 4 show normal white matter structure compared with Group 2. Sections were stained with $H \& E$ and images were acquired at $x 40$

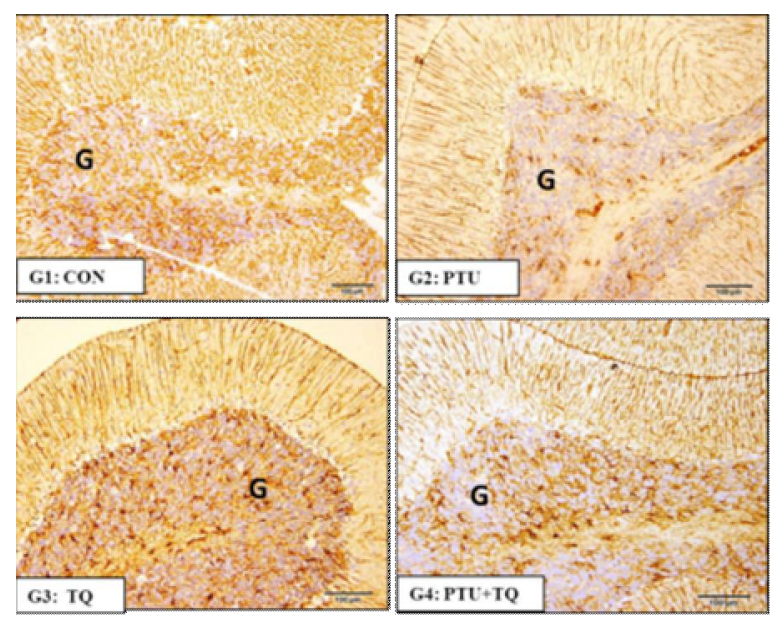

Figure 5: Photomicrographs of GFAP immune-stained sections from the cerebellum. Group 1 show small brown stained astrocytes within the Purkinje and granular cell layers and the white matter core with their process extending through the molecular layer. In group 2, a diffuse but significant decrease in GFAP expression is seen. Group 3 sections reveal similar GFAP expression as that observed in group 1. Group 4 sections have enhanced GFAP expression compared with that in group 1.

\section{Stereology: numerical density and total number of granular cells}

In the PTU-treated group, the numerical density of granular cells in the granular layer was 49.42 $\%$ (Figure 7). The administration of TQ significantly increased the numerical density of granular cells to $82.75 \%$ in Group 4 (PTU + TQ) (Figure 7). In addition, the total number of granular cells in hypothyroid rats treated with $\mathrm{TQ}$ 
(Group 4) increased compared with the untreated group (Group 2, Figure 8).

\section{DISCUSSION}

PTU is a well-known thyrotoxicant that can result in hypothyroidism when used for the management of overactive thyroid [19]. In this study, TQ was tested for its possible role in protection against PTU-induced histological and immunohistochemical changes in rat cerebellar cortex. Administration of TQ was found to prevent the increased body weight experienced by animals treated with PTU, and was related to an improvement in thyroid function tests. Thyroid hormone profiles in animals treated with $\mathrm{TQ}$ showed normal TSH, T3, and T4 levels. An increase in body weight and altered thyroid hormone levels are indicators of hypothyroid status [20].

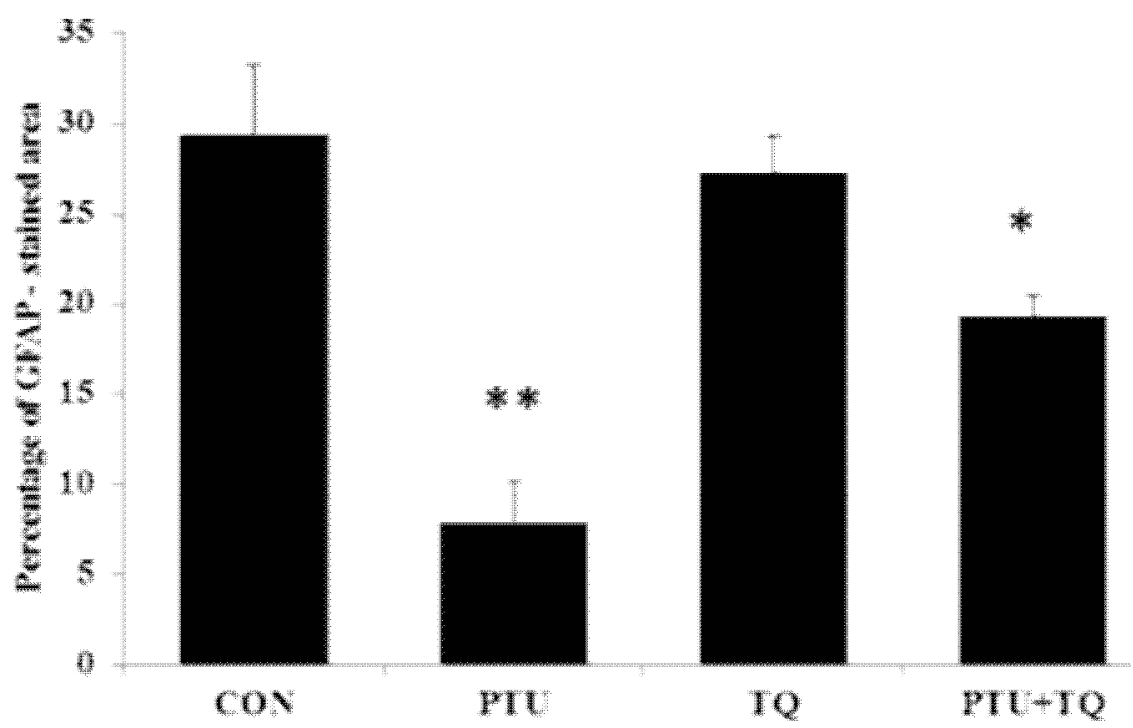

Figure 6: The percent area of the GFAP stained astrocytes. One-way analysis of variance (ANOVA) test was used for statistical analysis. When equal variance could be assumed, the post-hoc significant difference (LSD) $t$ test was applied. Values are expressed as mean $\pm S D$. ${ }^{* *}=P<0.01,{ }^{*}=P<0.05$

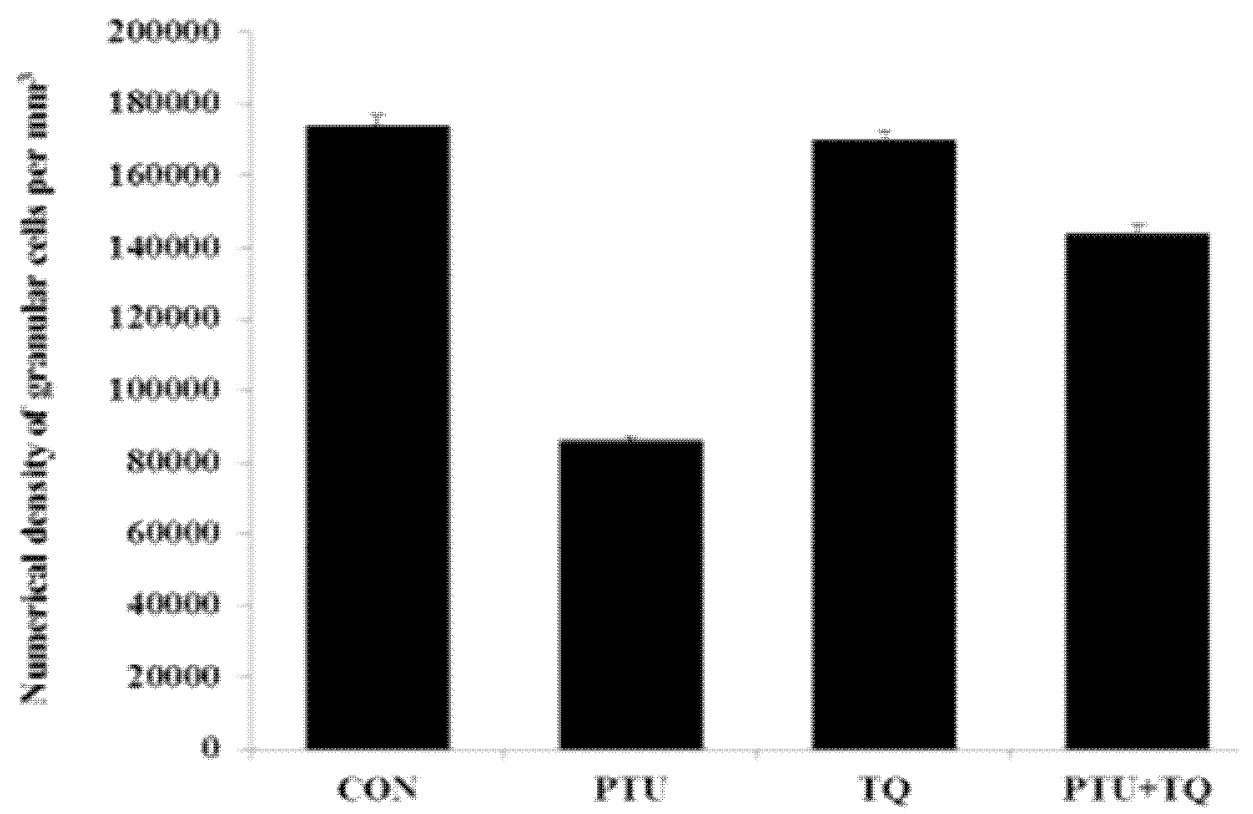

Figure 7:The numerical density of granular cells per $\mathrm{mm}^{3}$. Asignificant decrease is seen in numerical densityof granular cells is seen in groups 2 (PTU) and 4(PTU+ TQ). One-way analysis of variance (ANOVA) test was used to examine the difference between groups. When equal variance could be assumed, the post-hoc (LSD) t- test was used. Values are expressed as mean $\pm \mathrm{sd} .{ }^{* *}=\mathrm{P}<0.01,{ }^{*}=\mathrm{P}<0.05$. 


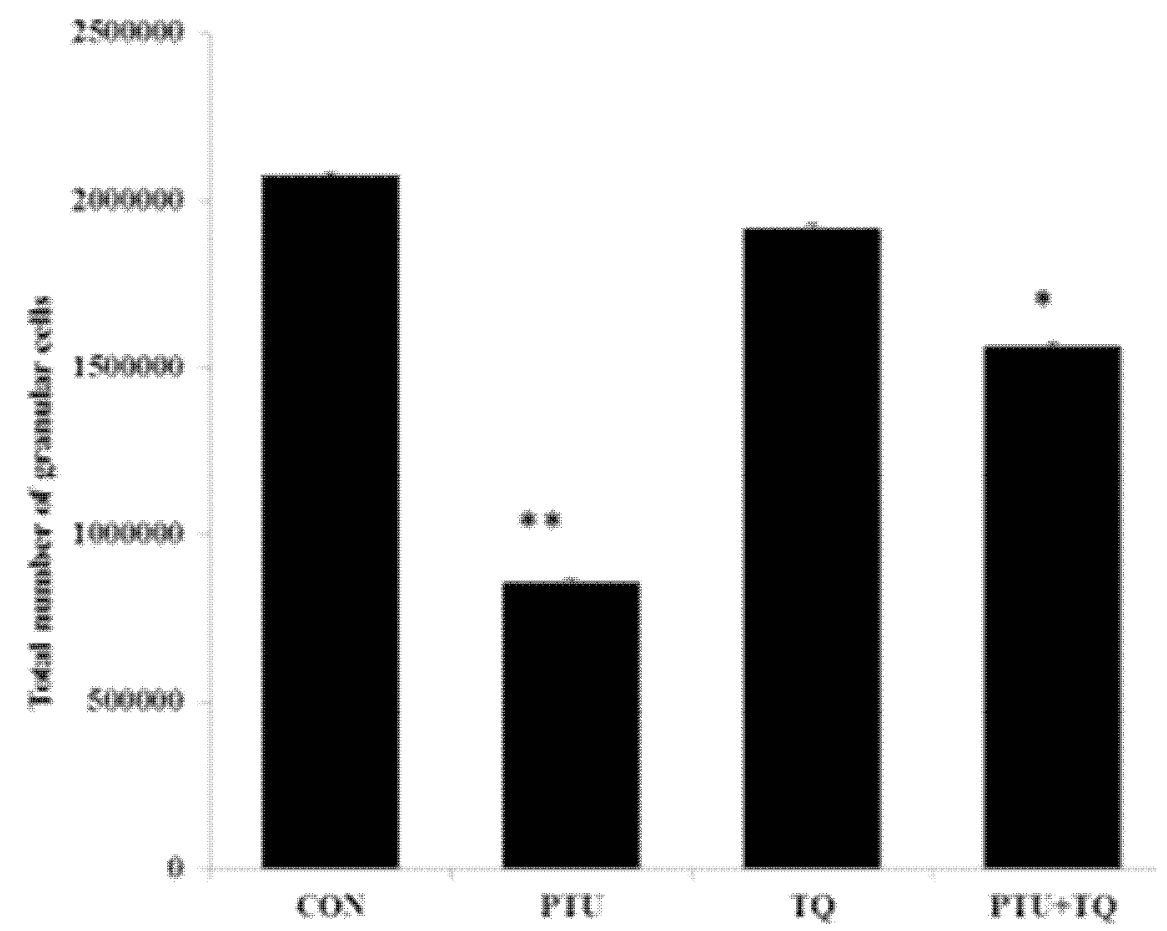

Figure 8: The total number of granular cells per $\mathrm{mm}^{3}$. Asignificant decrease in the total number of granular cells is seen in groups 2 (PTU) using the formula, $\mathrm{N}=\mathrm{NV} \times \mathrm{V}$ (ref). One-way analysis of variance (ANOVA) test was used to examine the statistical significance. When equal variance could be assumed, the post-hoc (LSD) $t$ test was used. Values are expressed as mean $\pm S D$. ${ }^{* *}=P<0.01,{ }^{*}=P<0.05$

The hypothyroidism induced by PTU was reflected in the histological and immunohistochemical features of the rat cerebellum samples. In the H\&E-stained sections, Purkinje cell degeneration and neuronal loss were observed after PTU treatment. Similar results have been reported in previous studies on thyroidectomy [21] or experimentally induced hypothyroidism [22]. Morphometric examination also showed that the numerical density of granular cells was markedly decreased in hypothyroid cases compared with the control. Previous studies have shown that the cerebellar microcircuit function is entirely dependent on synaptic integration in the granular layer [23].

GFAP expression was found to be significantly decreased in the cerebellar cortex after PTU treatment. The significant decrease in the percent area stained with GFAP seen in hypothyroid rats can potentially be explained by previous research. A previous study showed that astrocyte cell size, number of processes, and length of the processes determine astrocyte activity [24]. Interactions between astrocytes and neurons are thought to play a role in cell signaling, neurotransmission, and synapse modulation. Impairment of astrocyte-neuron interactions can critically influence the homeostasis of neuronal cells and may underlie the pathophysiology of many neurological disorders [25]. Degenerative neuronal insults induced by PTU are reportedly evoked by oxidative stress [22]; therefore, TQ could act to prevent the hypothyroid cerebellar damage resulting from oxidative stress [26]. In addition, a previous study showed that TQ had antioxidant activity and protected against oxidative stress in hypothyroid rats [27]. A similar mechanism could explain why TQ protected the cerebellum from PTU-induced damage in this study.

\section{CONCLUSION}

$T Q$, the active antioxidant ingredient of Nigella sativa, could be a beneficial natural candidate to counteract the unintended side effects in the cerebellum that result from treatment with antithyroid drugs.

\section{DECLARATIONS}

\section{Acknowledgement}

The authors acknowledge with thanks the support of the Scientific Chair of Yousef Abdullatif Jameel of Prophetic Medical Applications, King Abdulaziz University, Jeddah, Saudi Arabia for their support for this study.

\section{Conflict of Interest}

No conflict of interest associated with this work. 


\section{Contribution of Authors}

The authors declare that this work was done by the authors named in this article and all liabilities pertaining to claims relating to the content of this article will be borne by them.

\section{Open Access}

This is an Open Access article that uses a funding model which does not charge readers or their institutions for access and distributed under the terms of the Creative Commons Attribution License (http://creativecommons.org/licenses/by/ 4.0) and the Budapest Open Access Initiative (http://www.budapestopenaccessinitiative.org/rea d), which permit unrestricted use, distribution, and reproduction in any medium, provided the original work is properly credited.

\section{REFERENCES}

1. Konarski JZ, McIntyre RS, Grupp LA, Kennedy SH. Is the cerebellum relevant in the circuitry of neuropsychiatric disorders? J Psychiatry Neurosci 2005; 30(3): 178-186.

2. Reiman EM, Chen K, Alexander GE, Caselli RJ, Bandy $D$, Osborne D, Saunders AM, Hardy J. Functional brain abnormalities in young adults at genetic risk for late-onset Alzheimer's dementia. Proc Natl Acad Sci 2004; 101(1): 284-9.

3. Desai J, Yassa L, Marqusee E, George S, Frates MC, Chen MH, Morgan JA, Dychter SS, Larsen PR, Demetri GD, Alexander EK. Hypothyroidism after sunitinib treatment for patients with gastrointestinal stromal tumors. Ann Intern Med 2006; 145: 660-664.

4. Zeisel SH. Regulation of nutraceuticals. Science 1999; 285: 1853-1855.

5. Hussain DAS, Hussain MM. Nigella sativa (black seed) is an effective herbal remedy for every disease except death - a Prophetic statement which modern scientists confirm unanimously: A review. Advancement in Medicinal Plant Research 2016; 4(2): 27-57.

6. Suzuki M, O'Neal RM. Effects of therapeutic and toxic doses of propylthiouracil in rats. J Pharmacol Exp Ther. 1967; 155: 345-351.

7. Declaration of Helsinki. 18th World Medical Association General Assembly, Helsinki Finland, June, 1964, 29th World Medical Association General Assembly, Tokyo, Japan, October, 1975; 35th World Medical Association General Assembly, Venice, Italy, October, 1983; 41st World Medical Association General Assembly, Hong Kong, September 1989; 48th World Medical Association General Assembly, Somerset West, Republic of South Africa, October, 1996; 52nd World Medical Association General Assembly, Edinburgh, Scotland, October 2000.
8. Khalawi AA, Al-Robai AA, Khoja SM and Soad shaker Ali. Can Nigella Sativa Oil (NSO) Reverse Hypothyroid Status Induced by PTU in Rat? Biochemical and Histological Studies. Life Science Journal 2013; 10(20): 802-811.

9. Zoeller RT, Crofton KM. Mode of action: developmental thyroid hormone insufficiency-neurological abnormalities resulting from exposure to propylthiouracil. Crit Rev Toxicol. 2005; 35(8-9): 771-781.

10. Badary OA, Abdel-Naim AB, Abdel-Wahab MH, Hamada $F M$. The influence of thymoquinone on doxorubicininduced hyperlipidemic nephropathy in rats. Toxicol 2000; 143 (3): 219-226.

11. Gilbert ME, Paczkowski C. Propylthiouracil (PTU)induced hypothyroidism in the developing rat impairs synaptic transmission and plasticity in the dentate gyrus of the adult hippocampus. Brain Res Dev Brain Res 2003; 145(1): 19-29.

12. Dlugos CA, Pentney RJ. Quantitative immunocytochemistry of glia in the cerebellar cortex of old ethanol-fed rats. Alcohol 2001; 23(2): 63-9.

13. Hosseini-Sharifabad M, Sabahi A. Stereological estimation of granule cell number and purkinje cell volume in the cerebellum of noise-exposed young rat. Iran J Med Sci 2014; 39(4): 387-90.

14. Drury RA, Wallington EA. Carlton's Histological Techniques. ' 6 th ed.; Oxford University press. London 1983; 139 - 303.

15. Shi SR, Key ME, Kalra KL. Antigen retrieval in formalinfixed, paraffin-embedded tissues:an enhancement method for immune-histochemical staining based on microwave oven heating of tissue sections. J Histochem Cytochem 1991; 39 (6): 741-8.

16. Mayhew TM, Gundersen HJG. If you assume, you can make an ass out $U$ and me": a decade of the disector for stereological counting of particles in 3D space. $J$ Anat. 1996; 188: 1-15.

17. Howard CV, Reed MG. Unbiased stereology: Three dimensional measurements in microscopy. Oxford: BIOS Scientific 1998.

18. West MJ, Slomianka L, Gundersen HJG. Unbiased stereological estimation of the total number of neurons in the subdivisions of the rat hippocampus using the optical fractionator. Anat Rec 1991; 231 (4): 482-497.

19. Bahn RS, Burch HS, Cooper DS, Garber JR, Greenlee CM, Klein IL, Laurberg P, McDougall IR, Rivkees SA, Ross D, Sosa JA, Stan MN. The Role of Propylthiouracil in the Management of Graves' Disease in Adults: report of a meeting jointly sponsored by the American Thyroid Association and the Food and Drug Administration. Thyroid 2009; 19 (7): 673-674.

20. Maldjian $P D$, Chen $T$. Is visual assessment of thyroid attenuation on unenhanced CT of the chest useful for detecting hypothyroidism? Clin Radiol. 2016; 71(11): 1199. e9 - 1199. e14.

Trop J Pharm Res, May 2017; 16(5): 1036 
21. Ahmed Z, Asi YT, Sailer A, Lees AJ, Houlden H, Revesz $T$, Holton JL. The neuropathology, pathophysiology and genetics of multiple system atrophy. Neuropathol Appl Neurobiol. 2012; 38: 4-24.

22. Jena S, Anand C, Chainy GB, Dandapat J. Induction of oxidative stress and inhibition of superoxide dismutase expression in rat cerebral cortex and cerebellum by PTU-induced hypothyroidism and its reversal by curcumin. Neurol Sci. 2012; 33(4): 86973.

23. Seja PM, Schonewille G, Spitzmaul A, Badura I, Klein $Y$, Rudhard W, Wisden C, Hübner C, De Zeeuw and Jentsch T. Raising cytosolic Cl(-) in cerebellar granule cells affects their excitability and vestibuloocular learning. EMBO Rep. 2012; 31 (5): 1217-30.
24. Muranyi M, Ding $C$, He $Q$, Lin Y, Li PA. Streptozotocininduced diabetes causes astrocyte death after ischemia and reperfusion injury. Diabetes 2006; 55(2): 349-55.

25. Ricci G, Volpi L, Pasquali L, Petrozzi L, Siciliano G. Astrocyte-neuron interactions in neurological disorders. J Biol Phys. 2009; 35(4): 317-336.

26. Srikanta J, Gagan C, Jagneshwar D. Expression of antioxidant genes in renal cortex of PTU-induced hypothyroid rats: effect of vitamin $E$ and curcumin. Mol Biol Rep. 2012; 39: 1193.

27. Ayuoba NN, El-Shitanyc NA, Alamae MN. Thymoquinone protects against hypothyroidism-induced cardiac histopathological changes in rats through a nitric oxide/antioxidant mechanism. Biomedical Research 2016; 27 (1): 93-102. 